\title{
Development of machine-building enterprises controlling
}

\author{
Ramil Mavlioutov ${ }^{1, *}$, Olga Chubenko ${ }^{1}$ \\ ${ }^{1}$ Volgograd State Technical University, 400005 Volgograd, the Russian Federation
}

\begin{abstract}
The article is devoted to the formation of controlling at the machine-building enterprises of Russia. The author's interpretation of the concept of controlling as management of an enterprise is given. Controlling allows to provide an organizational and information basis for making managerial decisions aimed at the effective development of an enterprise in the conditions of dynamically changing factors of the external and internal environment. The necessity of introduction of controlling at machine-building enterprises is justified; the effects of controlling are given. Finally, methods for assessing the economic feasibility of introducing controlling at machine-building enterprises are given.
\end{abstract}

In modern conditions, the effective management of engineering enterprises is hampered by a complex of factors. Among them there are such factors as the ever-increasing amounts of information, the complexity of the tasks to be solved, many circumstances of endogenous and exogenous origin, which are characterized by variability and unpredictability. The effectiveness of management of machine-building enterprises determines its economic efficiency and, ultimately, its viability. At the same time, the determinant of the latter is, first of all, the quality of managerial activity and, as part of it, controlling. In this article in order to increase the competitiveness of machine-building products, to increase the level of its innovation, to increase the manufacturability of production, the necessity to enter foreign markets, and to follow the policy of import substitution, we have attempted to form the basis for the further progressive development of controlling at Russian machine-building enterprises. Thus, the study is aimed at solving problems: to formulate the author's understanding of the category "controlling"; to systematize the factors that determine the necessity to introduce controlling in general and controlling the individual business processes of the enterprise; to consider the positive and negative effects of the introduction of controlling on various facets of the enterprise's activity; to study ways of the economic feasibility of implementing controlling at the enterprise.

Controlling is one of the new management tools for Russian enterprises in different industries and spheres of activity. But at the current moment in scientific circles, the theoretical base and the conceptual apparatus of controlling continue to form. Dietger Hahn puts also into this concept the system of integrated information support, planning and control [1]. In the USA, controlling is seen as a kind of audit and revision. The Russian scientists have also different points of view. For example, A.M. Karminskiy considers

\footnotetext{
*Corresponding author: ramil-2002@mail.ru
} 
controlling as a system management aimed at ensuring a long-term effective operation of the enterprise [2]. And, for example, V.B. Ivashkevich believes that controlling should be considered as a system of using economic information for the purposes of enterprise management [3]. G.A. Korolyova puts in this concept a system for improving management effectiveness in general [4].

On the basis of the analysis, it is determined that none of the definitions of controlling can be fully accepted. Nevertheless, in the context of this article, we, in accordance with the position of A.G. Zhakevich [5], we understand controlling as the management of an enterprise, which allows to provide an organizational and information basis for making managerial decisions aimed at the effective development of an enterprise in the conditions of dynamically changing factors of the external and internal environment.As of 2014, preceding the beginning of the current wave of the crisis of the national economy, a separate subdivision with controlling functional has only a quarter of large business entities, although some top managers of some $90 \%$ of Russia's industrial giants are somehow aware of it [6].

This background reveals the increasingly aggravated factors that determine the necessity of introducing controlling at the machine-building industry as a whole. They can be systematized in six directions.

1. Organizational structure. Most managers of the lower and middle level do not have a clear idea of the organizational structure of the enterprise. Top management is often characterized by the lack of not only regulated areas and levels of competence, but also areas of responsibility.

2. Nomenclature of products. The production program of most machine-building enterprises is characterized by a high degree of inertia, and hence a whole complex of interrelated circumstances, the main of which is an outdated model range, low consumer characteristics of the products.

3. Procurement logistics. The main factor here is the prevalence of the traditional method, when raw staff and materials are procured at the same time in the full required volume, over the operational method.

4. The state of fixed production assets. There is an obsolete physical and moral fixed assets for production purposes. The situation is exacerbated by the unsystematic planned preventive repairs.

5. Staff motivation. There are many cases of lack of interest in the results of work, which is due to the perception of the work performed as a duty. This lack of interest is also caused by the factors of the organizational structure considered above.

6. Information environment. This includes a small degree of transition to electronic document management, and the organization of information flows, as well as a lack of IT support and software.

Further, it will be logical to systematize the prerequisites for the introduction of controlling certain business processes of a machine-building enterprise based on these factors. To do this, let's refer to Figure 1.

It is necessary to note that within the frame of controlling products engineering is to provide specialized knowledge for solving technological and organizational issues [7].

Before the implementation of controlling, enterprise management should consider the positive and negative effects of its implementation. From the standpoint of economic activity, indicators of financial and economic activities in general, and indicators of liquidity, financial stability, profitability, business activity in particular, have a long-term stable trend of increase. At the same time, the cost of implementing the controlling system is relatively high and this fact leads to reduction of its availability to a large number of economically insolvent enterprises. From the point of view of staffing, the full implementation of controlling, providing for the establishment of an appropriate structural 
unit at the enterprise, for the most mobile, adaptive part of the workforce, creates opportunities for the career growth. However, there is a threat, first of all for the employees of the top management, whose deprivation of authority will rightly raise the question if not about the reduction, then about the revision of their wages.

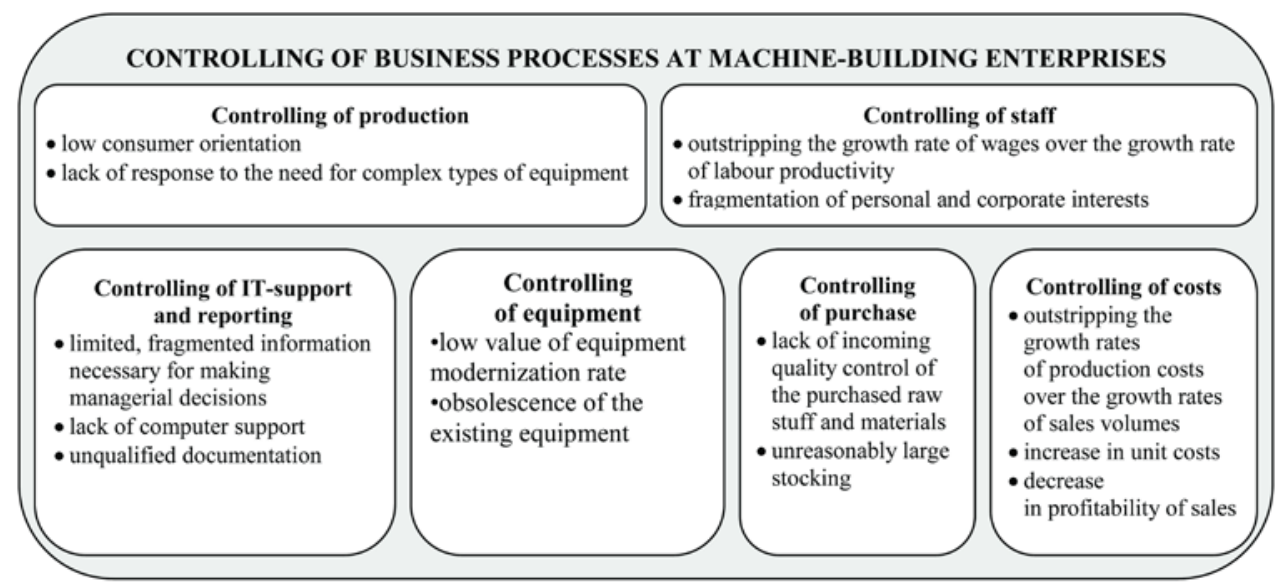

Fig. 1. Factors determining the necessity of implementation of controlling at Russian machinebuilding enterprises

If the management of the enterprise has decided in principle to implement controlling, it becomes necessary to assess the degree of economic feasibility of this. Consideration of the positions of a wide range of researchers [8-12] led to the conclusion that at the current time there is no standard solution to this problem. At the same time, the problem is complicated by the necessity to estimate the effectiveness of controlling at various stages of the life cycle of a machine-building enterprise: at the stage preceding the introduction of controlling when its expected results are estimated; in the process of the controlling system, when it becomes necessary to assess the effectiveness of controlling from the standpoint of understanding the necessity for its modernization. The multitasking of controlling estimation has given us reasons to identify a number of methods for assessing the economic feasibility of introducing controlling, which, in turn, allowed to create the methodical apparatus of estimation already functioning at the enterprise controlling system.

Estimation of expected results of introduction of controlling in the enterprise can be made by the following methods.

1. Correlation of the result and the costs applied to its achievement. The basis of the approach is the comparison of the effect that is achieved by the introduction of controlling, with the costs that are caused by the introduction. This approach can be formalized by the following equation:

$$
E_{i}=\frac{R_{i}}{C_{i}}, i=\overline{1, n}
$$

where $E_{i}$ is the effect,

$R_{i}$ is the result,

$C_{i}$ is the costs.

The role $E_{i}$ of can belong to the effects of different genesis: the economic, technological, information, social, image one, etc. Hence the cumulative effect of the introduction of controlling at the enterprise is determined by the equation: 


$$
E=\sum_{i=1}^{n} E_{i}
$$

This method is characterized by two drawbacks. Firstly, it is difficult, if not impossible, to quantify (especially from the point of view of finances) results within the framework of individual effects (for example, social effects). The costs caused by the introduction of controlling are also difficult to structure within the framework of correlation with this or that effect. Secondly, the approach does not take into account the influence of uncertain factors of endogenous and exogenous origin. This uncertainty causes the necessity to use tools that would allow to take into account the unavoidable uncertainty of the internal and external environment of the enterprise. To these tools can be attributed the apparatus of odd sets.

2. The indeterminate value of the payback of the introduction of controlling. Let's assume that it is possible to estimate with the set interval: the amount of the costs caused by the introduction of controlling (denoted as $\left[C_{1}, C_{2}\right]$ ); the value of the increase in the financial flow due to controlling (denoted as $\left[\mathrm{CF}_{1}, C F_{2}\right]$ ). Hence the definition of the payback of the introduction of controlling (denoted as $\left[E_{1}, E_{2}\right]$ ) is made through the equation:

$$
\left[E_{1}, E_{2}\right]=\frac{\left[C F_{1}, C F_{2}\right]}{\left[C_{1}, C_{2}\right]}
$$

Taking into account operations with positive definite fuzzy numbers [13], we can represent the equation (3) in the following form:

$$
\left[E_{1}, E_{2}\right]=\frac{\left[C F_{1}\right]}{\left[C_{2}\right]}, \frac{\left[C F_{2}\right]}{\left[C_{1}\right]}
$$

So, the payback of implementing controlling at the enterprise is estimated in intervals. At the same time, there is a necessity to estimate the probability of recoupment of the introduction of controlling. To do this, we resort to the graphical interpretation (Figure 2), which was formed by the intersections of the interval estimation of the financial flow increase due to the introduction of controlling, and the interval estimation of the costs caused by this implementation, as well as the bisectors of the $C-0-C F$ angle. In this case, the introduction of controlling will come to the payback when $C F>C$. And the probability of recoupment of the introduction of controlling is determined by the ratio of the area of the cost recovery zone to the total area of the rectangle, which is formed by the boundaries of the fuzzy numbers of the expected increase in the financial flow and the expected costs.

The equation (4) can also be applied in the case of an estimation of the recoupment of measures to modernize the controlling system already in place at the enterprise. In this case, the costs of upgrading the controlling system are in the role of $\left[C_{1}, C_{2}\right],\left[C F_{1}, C F_{2}\right]$ assumes the role of the financial flow increase caused by the modernization of the controlling system, and $\left[E_{1}, E_{2}\right]$ is viewed as a payback for the modernization of the controlling system. 


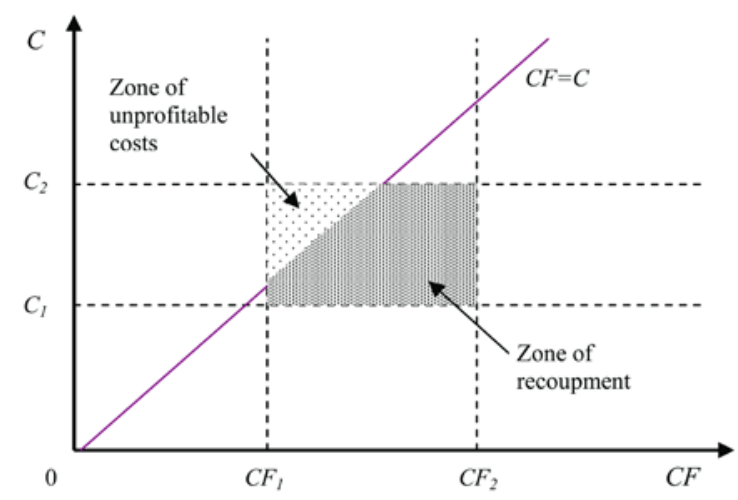

Fig. 2. Estimation of recoupment of costs of implementation of controlling at machine-building enterprises

Along with this, DuPont equation (The DuPont System of Analysis) allows us to formulate a factor model, which makes the possibility to evaluate the influence of a group of factors on profit growth, which is caused by the introduction of controlling at the enterprise:

$$
\Delta P=\frac{P^{\prime}}{I Q} \times \frac{I Q}{V S^{\prime}} \times \frac{V S^{\prime}}{V S_{0}} \times \frac{\Delta P}{P^{\prime}} \times V S_{0},
$$

where $\Delta P$ is the gain of profit, caused by introduction at the enterprise of controlling

$P^{\prime}$ is the profit of the enterprise that introduced controlling,

$I Q$ is the quality of knowledge and skills available to the controller (an employee whose duties include controlling) and that enable to perform work effectively,

$V S^{\prime}$ is the volume of sales of the enterprise on which controlling is introduced,

$V S_{0}$ is the volume of sales of an enterprise on which controlling has not been implemented,

Along with methods based on monetary measurements, non-monetary measurements are applicable to monitor the effectiveness of controlling at a machine-building enterprise. In our opinion, this method can be the indicator of satisfaction with the work of employees performing the functions of controllers and controlling service in general. It is based on scoring based on the weights of the criteria. In general, the indicator of satisfaction with the functioning of controlling at a mechanical engineering enterprise is proposed to be calculated using the equation:

$$
S=\sum_{i=1}^{n} Z_{i, \text { relative }} \times s g_{i},
$$

where $Z_{i, \text { relative }}$ is the ratio of the value of the criterion in the reporting period $\left(Z_{i, a p}\right)$ to its value in the base period $\left(Z_{i, b p}\right)$, that is $Z_{i, \text { relative }}=Z_{i, a p} / Z_{i, b p}$,

$s g_{i}$ is the weight of the criterion.

The system of criteria is formed by an expert method with at least five (more criteria increase the objectivity of the estimation), each of which is assigned its own weight. These criteria must take into account the specifics of the enterprise: industry identity, features of the nomenclature of the products, consumers, suppliers, etc. Objectively, this method is 
very laborious from the standpoint of forming an adequate list of criteria. However, the expected effectiveness of its application clearly speaks in its favour.

So, for the national economy, we see the achievement of the aims of increasing the adaptability of enterprises in the machine-building industry to the changing conditions of their functioning in the implementation of controlling. The essence of the implementation of controlling is the management of an enterprise that provides an organizational and information basis for making appropriate managerial decisions. The management of the majority of domestic enterprises at the moment is not fully aware of the risks that they will suffer in the medium and long term. The factors systematized by us fully formulate them, which made it possible to determine the prerequisites for the implementation of controlling certain business processes of machine-building enterprises. This process is hampered by a number of factors of the external environment of enterprises, among which is the increase in instability, which, among other factors, reduces the predictability of the results of financial and economic activities. In this connection, a set of methods for estimation not only the economic feasibility of introducing controlling at machine-building enterprises, but also the justification for the modernization of the already existing controlling system at the enterprise, was proposed. The given methodological apparatus forms the basis for the establishment of controlling at Russian machine-building enterprises. In addition, the results of the study can be applied in the development of programs for the implementation of controlling by industrial enterprises of various industry affiliations.

\section{References}

1. D. Hahn, PuK: Planung und Kontrolle, Planungs- und Kontrollsysteme, Planungs- und Kontrollrechnung (Springer-Verlag, Heidelberg, 2013)

2. A.M.Karmibskiy, N.I.Olenev, A.G.Primak, S.G.Falko, Controlling in business (Finance and statistics, Moscow, 2002) (in Russian)

3. V.B. Ivashkevich, Controlling: essence and purpose. Accounting, 7, 8-12 (1991) (in Russian)

4. G.A. Koroleva, Development of the controlling concept in modern management. Herald of Tver State University. Series: Economics and Management, 3, 78-84 (2017) (in Russian)

5. A.G. Zhakevich, Controlling is a modern industrial enterprise management system. Microeconomics, 2, 26-28 (2016) (in Russian)

6. P.A. Petrov, Preconditions and conditions for the development of controlling in domestic enterprises. Economic and Human Sciences, 11, 102-111 (2014) (in Russian)

7. R. Mavlioutov, E. Butenko1, R. Menyailova, On the estimation of feasibility of engineering services use by machine-building enterprises. MATEC Web of Conferences, 129 (2017)

8. V.P. Bozhko, A.M. Batkovskiy, M.A. Batkovskiy, Tools for estimation the controlling system. Economics, statistics and informatics, 3, 115-119 (2013) (in Russian)

9. R. Ding, Key project management based on effective project thinking (Springer Berlin Heidelberg, Berlin, 2015)

10. P. Harmon, Business Process Change (Elsevier Inc., San Francisco, 2007)

11. R.B. Morland, A.J. Gagglione, Business and finance: Performance and management (Nova Science Publishers, New York, 2011)

12. J.R.S. Fraser, B.J. Simkins, The challenges of and solutions for implementing enterprise risk management. Business Horizons, 59, 689-698 (2016)

13. E.G. Gridina, A.N. Lebedev, L.K. Radionova, A Brief introduction to the theory of fuzzy sets (Publishing house of MPEI, Moscow, 2010) (in Russian) 